\title{
Функциональные оптические элементы и устройства терагерцовой фотоники на основе
} метаповерхностей

\author{
С.А. Кузнецов ${ }^{1,2,3)}$, А.В. Гельфанд ${ }^{1)}$, В.Н. Федоринин ${ }^{1)}$, А.В. Аржанников ${ }^{2,3)}$, Н.А. Николаев ${ }^{4)}$ \\ ${ }^{1}$ Новосибирский филиал Института физики полупроводников им. А.В. Ржанова СО РАН "КТИПМ", \\ Новосибирск, 630090, пр. Академика Лаврентьева, 2/1 \\ ${ }^{2}$ Новосибирский государственный университет, Новосибирск, 630090, Пирогова, 2 \\ ${ }^{3}$ Институт ядерной физики им. Г.И.Будкера СО РАН, Новосибирск, \\ 630090, пр. Академика Лаврентьева, 11 \\ ${ }^{4}$ Институт автоматики и электрометрии СО РАН, Новосибирск, \\ 630090, пр. Академика Коптюга, 1 \\ тел:+7 (383) 363-42-95, эл. почта: sakuznetsov@nsm.nsu.ru
}

DOI 10.34077/RCSP2019-84

Освоение диапазона терагерцовых (ТГц) частот электромагнитного спектра (0,1-10 ТГц) делает актуальными задачи разработки и изготовления эффективных оптических элементов для управления характеристиками пучков ТГц-излучения. С инструментальной точки зрения данный спектральный диапазон, соответствующий интервалу длин волн $30 \div 3000$ мкм, удобно позиционирован между примыкающими к нему СВЧ и ИК областями, поскольку позволяет сочетать в терагерцовой аппаратуре инструментальные решения как оптической, так и микроволновой техники. Примером таких решений служат тонкие планарные метало-диэлектрические структуры субволновой топологии, известные в технологии метаматериалов как «метаповерхности» (МП). МП являются, как правило, резонансными электродинамическими структурами, которые эксплуатируются в режиме, когда их характерные резонансные частоты лежат значительно ниже точки возбуждения высших дифракционных гармоник, что отличает такие структуры от дифракционных решеток. Последнее достигается малостью периода расположения элементарных ячеек МП в ее латеральной плоскости в сравнении с рабочей длиной волны. Существенно, что амплитудные, фазовые и поляризационные характеристики МП в заданной полосе частот определяются дизайном ее ячеек, соответствующий выбор которого обеспечивает требуемые функциональные свойства МП-устройств. Последние выгодно сочетают малость толщины/веса и высокую эффективность, которая зачастую не может быть достигнута в рамках решений классической оптики. При этом в ТГц-диапазоне характерный размер элементов топологического рисунка МП в большинстве случаев составляет от нескольких единиц до сотен мкм, что позволяет применять для его производства сравнительно недорогие и хорошо отработанные литографические технологии.

В настоящем докладе представлен обзор экспериментальных результатов по разработке оптических элементов и устройств на основе метаповерхностей традиционных и новых конфигураций, которые предназначены как для автономного применения, так и для интеграции с различными метрологическими системами, работающими в области частот от сотни ГГц до нескольких ТГц. Составляя неотъемлемую часть российской элементной базы радиофотоники, разработанные элементы в ряде случаев опережают по функциональным характеристикам отечественные и зарубежные аналоги. Обсуждаются вопросы электродинамического моделирования, технологического производства, спектральной характеризации, а также практического использования следующих типов терагерцовых МП-устройств и систем на их основе:

1) частотные фильтры различных видов: band-pass, low-pass, high-pass; дихроичные мультиплексоры пучков излучения; спектрорадиометрические системы на базе полосовых фильтров;

2) поляризаторы; преобразователи фазы и поляризации;

3) плоские фокусирующие элементы, включая голографические структуры;

4) ультратонкие резонансные поглотители и тепловые детекторы на их основе, включая многоканальные пироэлектрические линейки для спектральных и поляризационных измерений с пространственным разрешением;

5) перестраиваемые ЖК-устройства на основе высокоимпедансных поверхностей;

6) сенсоры тонкопленочных аналитов, включая SEIRA-структуры.

Исследования выполнены при частичной финансовой поддержке Российского фонда фундаментальных исследований (проекты РФФИ №1 8-02-00232, №1 8-29-20066). 